Historic, Archive Document

Do not assume content reflects current scientific knowledge, policies, or practices. 

Please Return If Undeliverable.

Postage Guaranteed

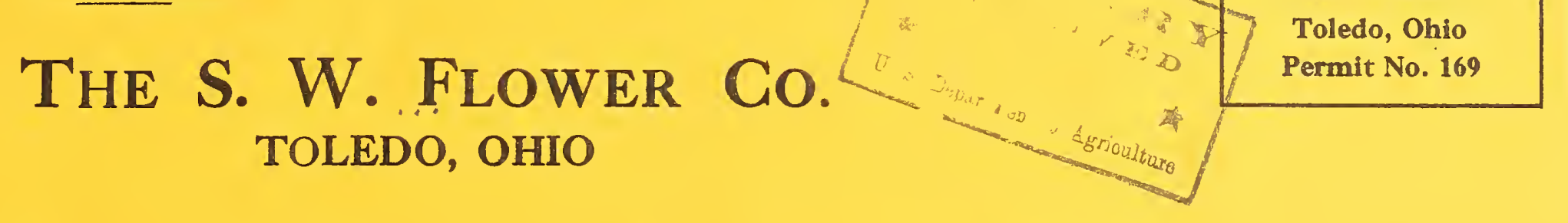

FIELD

DEPT.OF

SEED

WASHASW $N=0$ 。

MERCHANTS

U. S. Postage $1 \frac{1}{2}$ Paid Toledo, Ohio Permit No. 169 



\begin{tabular}{|c|c|c|c|}
\hline SEEDS & $\begin{array}{l}\text { Weight } \\
\text { Per Bu. }\end{array}$ & $\begin{array}{l}\text { Pounds } \\
\text { Per Aere }\end{array}$ & TIME OF SEEDII \\
\hline $\begin{array}{l}\text { Alfalfa, } \\
\text { broadcast. }\end{array}$ & 60 & $10-20$ & April-August \\
\hline Alsike, broadcast & 60 & $7-10$ & February-August \\
\hline Barley, drilled 8 & 48 & $72-120$ & March-May \\
\hline $\begin{array}{l}\text { Blue Grass, } \\
\text { broadcast.... }\end{array}$ & 14 & $15-20$ & Mar. Apr.-Jul. A \\
\hline $\begin{array}{l}\text { Buckwheat, } \\
\text { drilled } 8\end{array}$ & 48 & $35-60$ & June-July \\
\hline $\begin{array}{l}\text { Clover, Crimson } \\
\text { broadcast }\end{array}$ & 60 & $10-15$ & July-August \\
\hline $\begin{array}{l}\text { Clover, Red, } \\
\text { broadcast }\end{array}$ & 60 & $8-12$ & Feb. Apr.-August \\
\hline $\begin{array}{l}\text { Clover, Mammoth } \\
\text { broadcast............... }\end{array}$ & 60 & $8-12$ & Feb. Apr.-August \\
\hline $\begin{array}{l}\text { Clover, Sweet, } \\
\text { hulled, broadcast }\end{array}$ & 60 & $10-20$ & March-August \\
\hline $\begin{array}{l}\text { Clover, White } \\
\text { broadcast }\end{array}$ & 60 & $6-8$ & February-August \\
\hline $\begin{array}{l}\text { Fescue, Meadow } \\
\text { broadcast. }\end{array}$ & 12 & $15-20$ & Mar. Apr._July Au \\
\hline Flax, drilled 8 & 56 & $28-56$ & \\
\hline $\begin{array}{l}\text { Millet, German } \\
\text { drilled 8 }\end{array}$ & 50 & $25-50$ & \\
\hline $\begin{array}{l}\text { Millet, Hungarian } \\
\text { drilled 8.............. }\end{array}$ & 48 & $25-50$ & May-July \\
\hline $\begin{array}{l}\text { Orchard Grass } \\
\text { broadcast....... }\end{array}$ & 14 & $15-25$ & Mar. Apr.-Jul. Au \\
\hline $\begin{array}{l}\text { Peas, Canada, } \\
\text { drilled } 8\end{array}$ & 60 & $120-180$ & March-April \\
\hline $\begin{array}{l}\text { Rape, Dwarf } \\
\text { Essex, broadcast }\end{array}$ & 50 & $5-8$ & April-July \\
\hline $\begin{array}{l}\text { Red Top, hulled, } \\
\text { broadcast. }\end{array}$ & 14 & $10-15$ & Mar. Apr.-Jul. A \\
\hline $\begin{array}{l}\text { Rye, Winter, } \\
\text { drilled } 8 . . . . . .\end{array}$ & 56 & $85-115$ & September-Nov。 \\
\hline $\begin{array}{l}\text { Soy Beans, } \\
\text { drilled } 8 . . . .\end{array}$ & 60 & $60-120$ & May-June \\
\hline $\begin{array}{l}\text { Timothy, } \\
\text { broadcast. }\end{array}$ & 45 & $10-15$ & Mar. July_Sept. \\
\hline $\begin{array}{l}\text { Vetch, Spring, } \\
\text { drilled } 8\end{array}$ & & $30-60$ & April-May \\
\hline $\begin{array}{l}\text { Vetch, Winter, } \\
\text { drilled 8........... }\end{array}$ & 60 & $30-60$ & July-September \\
\hline $\begin{array}{l}\text { Wheat, Winter, } \\
\text { drilled } 8 . . . . .\end{array}$ & 60 & $75-135$ & September-Oct. \\
\hline $\begin{array}{l}\text { Wheat, Spring, } \\
\text { drilled 8.......... }\end{array}$ & & $90-120$ & April \\
\hline
\end{tabular}


If you have seed to sell send samples with lowest prices

Before buying take our qualities into consideration

Samples on request

"The Best is the Cheapest"

We sell for future shipment

If interested ask for quotations

\section{Better Seeds}

